\title{
Endovascular treatment of carotid-cavernous vascular lesions
}

\section{Tratamento endovascular das lesões vasculares carótido-cavernosas}

Guilherme Brasileiro de Aguiar, ACBC-SP1; João Miguel Silva1; Aline lariessy Paiva1; Maurício Jory; Mario luiz Conti'; José Carlos Veiga, TCBC-SP ${ }^{1}$.

\section{A B S T R A C T}

Objective: to evaluate the endovascular treatment of vascular lesions of the cavernous segment of the internal carotidartery (ICA) performed at our institution. Methods: we conducted a descriptive, retrospective and prospective study of patients with aneurysms of the cavernous portion of the ICA or with direct carotid-cavernous fistulas (dCCF) undergoing endovascular treatment. Results: we included 26 patients with intracavernous aneurysms and ten with dCCF. All aneurysms were treated with ICA occlusion. Those with dCCF were treated with occlusion in seven cases and with selective fistula occlusion in the remaining three. There was improvement of pain and ocular proptosis in all patients with dCCF. In patients with intracavernous aneurysms, the incidence of retro-orbital pain fell from $84.6 \%$ to $30.8 \%$ after treatment. The endovascular treatment decreased the dysfunction of affected cranial nerves in both groups, especially the oculomotor one. Conclusion: the endovascular treatment significantly improved the symptoms in the patients studied, especially those related to pain and oculomotor nerve dysfunction.

Keywords: Carotid-Cavernous Sinus Fistula. Embolization, Therapeutic. Carotid Artery Injuries.

\section{INTRODUCTION}

T treatment of lesions that compromise the cavernous sinus (CS) represents a challenge to neurosurgeons. Since Dolenc ${ }^{1}$ has comprehensively described the microsurgical anatomy, knowledge of the CS region has spread, allowing the development of new treatment techniques.

The increasing knowledge of the topographic anatomy related to the internal carotid artery (ICA) and its relationships with bones, dura mater (DM), venous spaces and cranial nerves (CN) changed the course of neurosurgical performance in CS lesions ${ }^{1}$. The development of modern neuroendocrine intervention techniques has widened the range of therapeutic options for vascular affections compromising the CS. However, controversy persists regarding treatment.

The endovascular treatment of such lesions has presented several changes in recent years, especially due to the appearance of new technical resources ${ }^{2}$. Thus, the constant evaluation of its effectiveness is necessary to obtain better results, associated with progressively lower rates of morbidity and mortality.
The objective of the present study is to evaluate the endovascular treatment of vascular lesions - aneurysms and fistulas - that affect the intracavernous internal carotid artery in patients undergoing treatment in the São Paulo Holy Home.

\section{METHODS}

The project and the Informed Consent Form were previously approved by the Ethics in Research Committee under number 197/10.

It is a descriptive, retrospective and prospective study in which we evaluated 39 patients with intracavernous aneurysms (ICCAA) and direct carotidcavernous fistulas (dCCF), of whom 36 underwent endovascular treatment in the period of January 1, 2009 to December 31, 2012. We performed retrospective assessment through medical records review and prospective outpatient visits. All individuals had an outpatient follow-up for at least one year.

We included in the study patients with a diagnosis of dCCF who underwent endovascular treatment and ICA patients with intractable pain and/or

1 - Faculty of Medical Sciences, São Paulo Holy Home, Department of Surgery, Sao Paulo, Sao Paulo State, Brazil. 


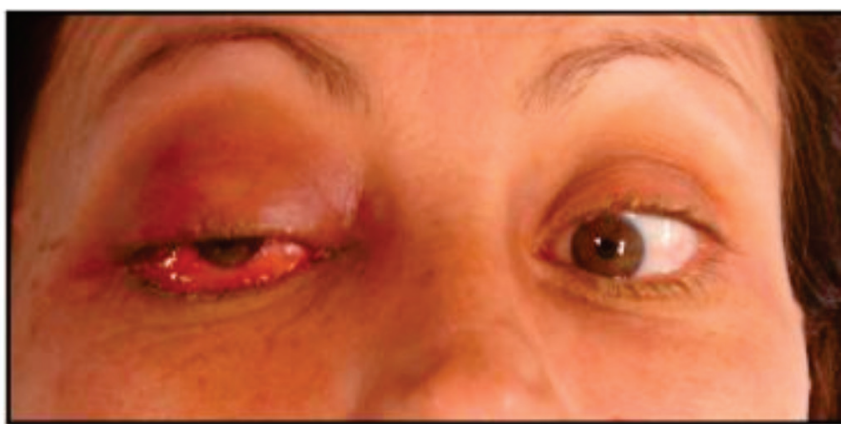

Figure 1. Patient with dCCF presenting with proptosis, ocular hyperemia and CN VI deficit on the right.

symptoms resulting from changes in CN III, IV, V or VI lasting less than or equal to six months and undergoing endovascular treatment.

We excluded patients who refused to participate in the study and patients with incomplete data records or for whom the variables assessment was impossible. We included the obtained data in spreadsheets and presented them in a descriptive way in tables and graphs.

\section{RESULTS}

Ten patients underwent endovascular treatment for carotido-cavernous fistulas, four of them male and six female. The mean age was 35.3 years. We observed previous trauma history in nine $(90 \%)$ patients, with the mean time interval between the trauma and the definitive treatment of 6.94 months. ICA occlusion was the method used in seven cases. The remaining three cases underwent balloon fistula occlusion. In total, 13 interventions were performed in the ten patients.

The previous evaluation of the patients with dCCF showed the presence of pain in nine of them.

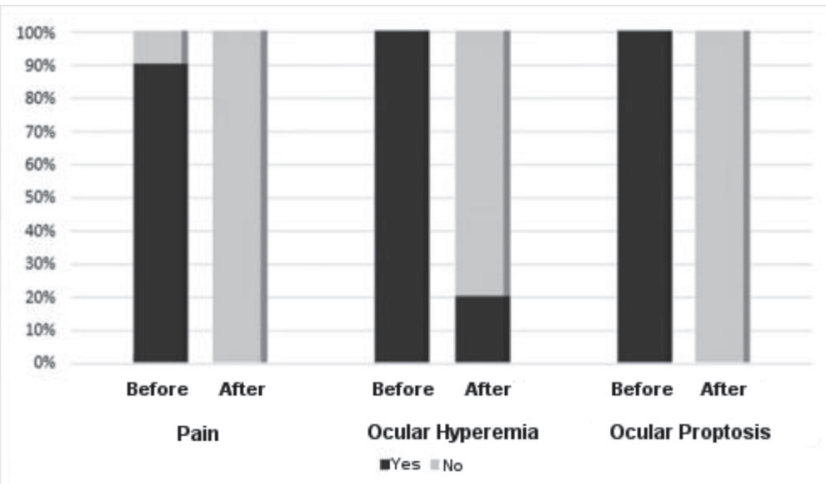

Figure 2. Clinical manifestations in patients with dCCF before and after endovascular treatment.
Ocular hyperemia, proptosis and oculomotor nerve involvement were present in all patients (Figures 1, 2 and 3). The trochlear nerve had altered function in four, the trigeminal in one and the abducent in seven (Figure 3). After the final therapeutic intervention, all patients presented without pain or ocular proptosis. We observed discrete residual ocular hyperemia in two patients. The function of the oculomotor, trochlear, trigeminal and abducent nerves remained altered in three, one, one and three patients, respectively (Figures 2 and 3).

The endovascular treatment of aneurysms of the cavernous segment of the internal carotid artery was performed in 26 patients. In these patients, the history of previous trauma was observed in three $(11.5 \%)$ who in fact had a traumatic pseudoaneurysm.

In the group of patients with non-traumatic aneurysms, two were male and 21 female. The mean age of treated patients was 54.35 years (Figure 4). We observed that the 23 patients of this subgroup had giant aneurysms. Only one patient (3.9\%) had another aneurysm at the time of diagnosis, which was subjected to microsurgical clipping prior to ICA therapeutic occlusion.

The therapeutic option used in all patients of this subgroup was the ICA endovascular occlusion of with coils. One patient, despite having an ICA occlusion test negative for deficits, evolved with motor deficit contralateral to the occluded side 72 hours after the procedure, being the only complication observed in this group.

In the preoperative evaluation, retro-orbital and periocular pain were present in 21 cases (91.3\%). We observed involvement of the oculomotor nerve ipsilateral

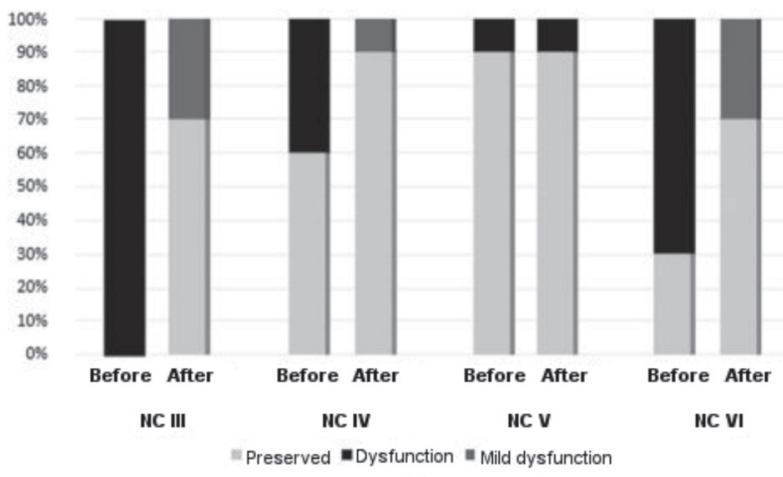

Figure 3. CN function of in patients with dCCF before and after endovascular treatment. 


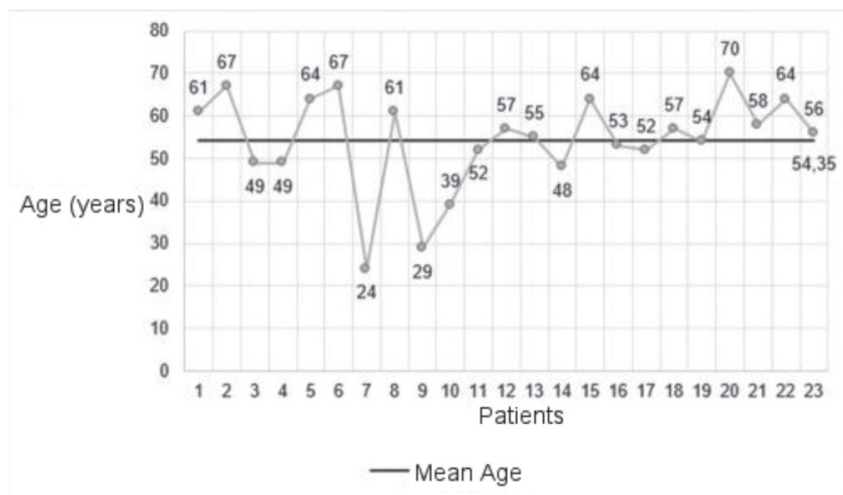

Figure 4. Distribution of the ages of patients with ICCAA.

to the aneurysm in 21 patients (Figure 5). Trochlear nerve injury was seen in $47.8 \%$ of cases. We found trigeminal nerve involvement in ten patients (43.4\%), and abducent nerve commitment in 19 (82.6\%) (Figure 6).

In the postoperative evaluation, there was no pain in 15 patients (65.2\%). After treatment, retroorbital pain was present in $34.8 \%$, with lower intensity. The involvement of the oculomotor nerve remained in 11 patients (47.8\%). The trochlear nerve was clinically altered in three and the injury of the trigeminal and abducent nerves was evident in less intensity in four and eleven patients, respectively (Figure 6).

ThreepatientswithICA traumatic pseudoaneurysms were treated with ICA occlusion. Two patients underwent ICA occlusion with balloons, and one, with coils. We observed an iatrogenic etiology in one of these cases, resulting from a previous approach of the Sella region by transsphenoidal endoscopic surgery. This same patient later evolved with the formation of dCCF, being therefore included in two of this work's groups.

Inthesubgroup of patientswith pseudoaneurysms, a single patient was submitted to treatment immediately

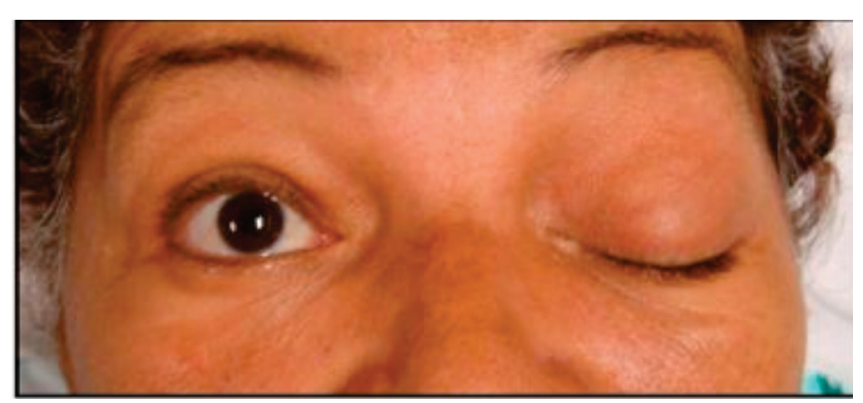

Figure 5. ICCAA patient presenting left palpebral ptosis due to CN III deficit. after the traumatic injury, even during the same anesthetic act, corresponding to the case that suffered injury during a surgical procedure and, therefore, no complaints were recorded regarding $\mathrm{CN}$ deficits. Another patient had only a CN VI deficit before treatment. The last patient in this subgroup had a deficit of $\mathrm{CN}$ III and VI, in addition to retroocular pain. After treatment, all patients were symptom-free.

\section{DISCUSSION}

The dCCF represent high-flow lesions ${ }^{3}$ and usually have a traumatic etiology ${ }^{4-6}$, as found in $90 \%$ of the patients in this study. The only patient with this diagnosis who had no history of trauma supposedly had the fistula due to the rupture of the ICCAA. This situation accounts for up to $25 \%$ of dCCF.

The dCCF usually occurs in young male patients ${ }^{7}$, as this is the group most frequently affected by traumatic brain injury (TBI). Differently, we found $60 \%$ females in this study. The mean age of the treated patients was 35.3 years, corroborating data from the literature ${ }^{3,7}$. One patient, although not correlated with $\mathrm{TBI}$, presented dCCF after inadvertent laceration of the ICA during surgery for resection of a skull base tumor. This etiology is also well documented in the literature ${ }^{6-10}$.

The only patient who had no traumatic etiology presented emptying of the balloon used for the selective dCCF occlusion on the second day after treatment, which required a new therapeutic session with the need for ICA occlusion. The emptying of the balloon, often caused by

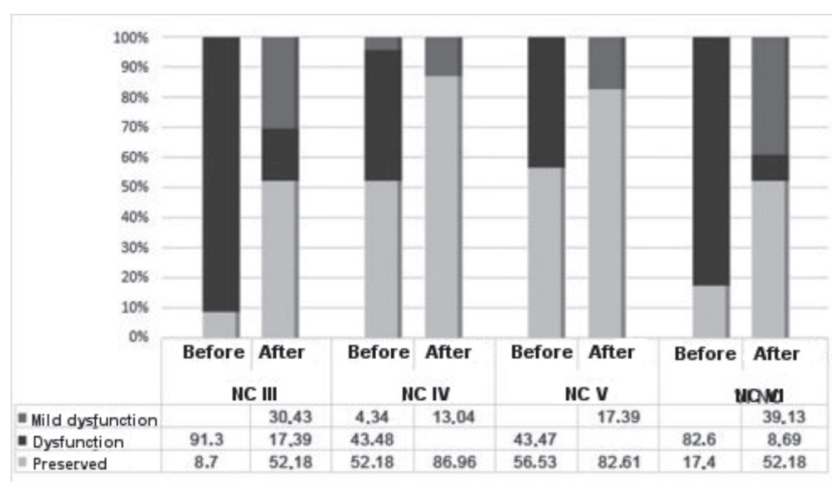

Figure 6. CN function in ICCAA patients before and after endovascular treatment. 
perforation, is usually described in association with dCCF of traumatic origin, in which bony spicules from fractures at the base of the skull8,11,12 may cause perforation of the balloon located in CS, especially when it is inflated.

The time elapsed between the beginning of the symptoms and the endovascular treatment was up to 21 months. In this context, we also observed that patients who remained untreated for a longer period had a lower possibility of improvement of the signs and symptoms presented, especially regarding ocular motricity and conjunctival hyperemia, although without significant statistical evidence. This observation reinforces the importance of early diagnosis and treatment ${ }^{3}$.

Data from the literature demonstrate clinical exuberance in the presentation of $d C C^{13}$. The most diverse clinical signs, such as conjunctival hyperemia and ocular proptosis, were present in all patients in the study. In addition, retro-ocular pain was a frequent symptom, present in $90 \%$ of patients. The rates of $\mathrm{CN}$ impairment found in this study are similar to those reported in publications ${ }^{2,7}$, as well as of symptoms improvement after treatment.

Some patientshave developed ophthalmoplegia. This is most commonly explained by the involvement of CNs responsible for extrinsic ocular movements ${ }^{2,7}$. However, this condition is facilitated by the appearance of edema of the intraorbital and periocular structures generated by venous engorgement ${ }^{3}$.

Diagnostic suspicion of dCCF is based on clinical findings ${ }^{14}$. When one suspects this condition, CT scan of the skull is usually requested as the first imaging examination, which may reveal ocular proptosis and, in contrast phase, venous engorgement and tortuosity of the involved ophthalmic vein, as well as $\mathrm{CS}^{14}$. This was the case with this study patients. All were submitted to CT scan of the skull showing the mentioned changes. The diagnostic sequence is based on carotid arteriography (CA), which, in addition to confirming the presence of the fistula and its venous drainage, is of fundamental importance for classification and therapeutic planning ${ }^{7}$. It is also useful in the investigation of other vascular lesions, such as: CS pseudoaneurysms and varicose veins ${ }^{7}$, or thrombosis of other venous sinuses.
As to management, once diagnosed, all cases were referred for endovascular treatment. Although there is report of cases of dCCF spontaneous cure ${ }^{15}$, there is currently no room for doubt as to whether or not to indicate treatment ${ }^{3,13}$. There is also consensus regarding the indication of endovascular intervention as a treatment ${ }^{3,6}$. Currently, authors differ basically regarding the necessity or not of the treatment immediately after the fistula diagnosis, and the best endovascular technique to be used.

For some authors, such as Halbach et al. ${ }^{16}$, treatment should be early, especially if there is intracranial hemorrhage, epistaxis, increased intraocular pressure, reduced visual acuity or progressive proptosis. The authors who advocate treatment at a later stage claim that, because of recent trauma, the ICA may present a high reactivity to endovascular navigation, which would lead to an increased risk of endothelial injury. In this study, patients were treated in the late phase.

Once the endovascular approach is indicated, the ideal treatment for dCCF is its exclusion from circulation, with preservation of blood flow by the ICA $3,5,8,11$ and this was the goal sought. Thus, we attempted the placement of a latex disposable balloon within the CS for selective fistula occlusion as the initial procedure for all patients. However, the selective occlusion of dCCF with preservation of the flow by the ICA was only definitively achieved in $30 \%$ of the patients. The high failure rate (70\%) in the preservation of ICA flow differs significantly from that recorded in the literature, which predicts a failure rate of around 10 to $20 \%{ }^{17}$.

The most common cause of failure of dCCF balloon selective occlusion is the presence of bone spicules within the CS, which would result in the balloon perforation after its positioning in the $\mathrm{CS}^{18}$. This usually occurs at the time of balloon insufflation. Balloon perforation at the time of inflation did not occur in this series. One of the cases presented emptying of the balloon in the late phase, corresponding to the only one not having TBI. Another acceptable explanation, which is consistent with the reality found, would be the difficulty of positioning the balloon inside the CS. Such a situation may be related to the small 
size of CS, which would make it difficult to inflate the balloon ${ }^{3}$, or even to the large dimensions of the fistulous orifice, which may have progressed during the time elapsed until diagnosis and treatment.

Patients submitted to dCCF balloon occlusion displayed no significant complications. There were no residual fistulas or thromboembolic complications that, although rare, are described ${ }^{3}$. However, one patient evolved with intracavernous pseudoaneurysm formation, which remained stable during angiographic follow-up for two years.

In cases of failure of the selective fistula occlusion, patients were candidates for ICA therapeutic occlusion. In most cases, this was accomplished with the placement of detachable balloons occluding the fistular tunnel and the ICA. In these patients, the ICA flow was directed almost exclusively to the fistula, and no occlusion test was required. We observed no complications related to ICA occlusion in this subgroup.

In the group of patients with intracavernous aneurysms, there was a predominance of female gender (84.6\%). This situation is in agreement with the existing publications ${ }^{19,20}$, although there is no known explanation for this. These lesions usually affect patients in the 5th and 6th decades of life ${ }^{20}$, and are commonly manifested by CNs compressive symptoms ${ }^{19}$. In this sample, the mean age at symptoms presentation was 52.2 years ${ }^{20,21}$. If only the group of non-traumatic ICA patients was considered, the mean age was 54.4 years. The increase in the age range of this subgroup is expected, since non-traumatic lesions affect older patients ${ }^{20}$.

Intracavernous aneurysms usually have their genesis linked to hemodynamic and atherosclerotic factors $^{20}$. A small proportion of the cases may be associated with TBI or direct ICA lesions ${ }^{20}$, in these situations being called traumatic pseudoaneurysms. We observed three patients with diagnosed traumatic pseudoaneurysms, representing $11.5 \%$ of the cases. Two of them were caused by closed head trauma and only one due to inadvertent ICA surgical injury.

All cases but the previously mentioned patient who suffered direct ICA injury during the surgical procedure were diagnosed from the compression symptomatology of the $\mathrm{CN}$ affected in the $\mathrm{CS}$ region. This is the most common presentation ${ }^{19-21}$. Thus, the patients had a clinical picture of retroocular pain, diplopia, ophthalmoparesis and trigeminal neuropathy in different degrees. The same symptoms and signs were found by other authors who investigated aneurysms involving the itracavernous Carotid Artery ${ }^{19,21}$. Although described in the literature ${ }^{19}$, none of the intracavernous ansurisms in this study were manifested by spontaneous subarachnoid hemorrhage (SSH).

SSH from an ICCAA is a rare phenomenon ${ }^{22}$. When present, it most often results from the expansion of the aneurysms into the subarachnoid space. This expansion occurs most frequently in aneurysms originating from the C2 segment of the ICA. Another mechanism for its occurrence would be erosion of the lateral wall by the giant aneurysms, or even of the medial wall, causing hemorrhage through the sellar diaphragm ${ }^{23}$.

According to Choulakian et al. ${ }^{24}$, to display CN compressive symptoms, the IcCAA should have diameters greater than $15 \mathrm{~mm}$. In our sample, 23 of the 26 aneurysms were considered giant (greater than $25 \mathrm{~mm}$ ), confirming this affirmation. The three remaining aneurysms were, in fact, pseudoaneurysms, with their symptoms associated with cranial trauma.

According to Vasconcellos et al. ${ }^{20}$, the most commonly encountered ICCAA symptoms were, in decreasing order of frequency: headache, diplopia due to CN IV dysfunction, retro-orbital pain, visual deficit and photophobia. In this study, the most commonly affected $\mathrm{CN}$, in descending order of frequency, were: oculomotor, abducent, trochlear and trigeminal. Still, retro-orbital pain was present in $84.6 \%$. As for pain, this group of patients with severe pain was the most benefited by the treatment, considering that no patient had uncontrollable pain after the endovascular therapy. The improvement in CN symptomatology obtained with endovascular treatment is in agreement with that found in the literature ${ }^{25,26}$. There was improvement in the function of at least one $\mathrm{CN}$ in all patients. This high rate of clinical improvement is also justified by the treatment 
being instituted at an early stage, when the symptoms had a less than six-month duration.

Regarding the diagnostic sequence employed, the majority of patients with IcCAA came to the service with complaints regarding $\mathrm{CN}$ compression, such as diplopia and painful ophthalmoplegia. These patients were initially submitted to head CT, which most of the time showed an intracavernous expansive lesion, adjacent to the ICA, with arterial flow. Magnetic resonance imaging (MRI) of the brain was performed to complement the diagnosis, which was able to better characterize the lesion, as well as to identify the presence of intra-aneurysmal thrombi. In sequence, cerebral angiography was performed with the purpose of diagnostic confirmation and therapeutic planning, often already associated with the ICA occlusion test.

From the conception of the present study, we only included patients who underwent IcCAA endovascular treatment by ICA occlusion. Thus, all treatment candidates were previously submitted to ICA occlusion test. Studies have shown that approximately $25 \%$ of the patients undergoing carotid occlusion without having undergone a carotid occlusion test developed cerebral infarctions and about $12 \%$ of them died as a result of the occlusion of one of the ICA. After incorporation of the occlusion test, these percentages were drastically reduced ${ }^{27}$. In this sample, 29 ICA occlusion tests were performed and only three patients presented deficits after temporary ICA occlusion. These patients were excluded from the study and referred for surgical treatment through bypass.

However, even patients who adequately tolerate this test may subsequently develop some type of deficit related to the artery occlusion. Only one patient had a late ischemia, with hemiparesis contralateral to the occluded carotid artery. This index is lower than the expected, based on data from the literature, which indicate a rate of up to $22 \%{ }^{28}$.

It is worth mentioning that the ICA therapeutic occlusion for ICCAA represents a procedure with low morbidity and mortality, taking into account that the alternatives, especially the microsurgical clipping or vascular bypass, have morbidity rates of around 5-10\% and mortality rates of $3-10 \%{ }^{29}$.
The treatment of ICCAA with ICA occlusion, although not the ideal option, is considered by many authors as the choice for this type of lesion ${ }^{21}$, with up to $90 \%$ improvement in the CNs compressive symptoms ${ }^{21}$. All The patients in the study showed improvement of at least one affected $\mathrm{CN}$.

The efficacy of carotid occlusion to induce thrombosis of the aneurysm is inversely proportional to the degree of existing collateral circulation. Thus, the more proximal the ICA aneurysm, the lower the potential influence of an eventual collateral flow, and therefore the greater the expectation of treatment success ${ }^{29}$. Therefore, carotid occlusion tends to be more effective for aneurysms of the petrous and cavernous segment because of the small number and caliber of the arterial branches. Aneurysms of the ophthalmic segment (paraclinoid) can also be treated by ICA occlusion, but the chances of thrombosis are smaller, especially due to the presence of the retrograde flow through the ophthalmic artery ${ }^{29}$.

ICA occlusion is believed to be more effective than the common carotid artery occlusion for ICCAA treatment ${ }^{28}$, although occlusion at one or other location is associated with similar incidences of aneurysmal thrombosis, reduced aneurysm volume and reduction of bleeding rates ${ }^{28}$. In the present study, all patients underwent selective ICA occlusion, considering that the preservation of the external carotid flow may be important for the maintenance of adequate cerebral flow.

Although not performed in the study patients, there are other options for the endovascular treatment of ICCAA. The use of flow diversion stent has emerged as an alternative in the search for the ideal treatment model of such lesions, since it aims to exclude the aneurysm from the circulation, preserving the ICA blood flow ${ }^{29}$. Although it may represent the standard ICCAA treatment, even the use of these stents can be followed by ischemic or hemorrhagic complications, often fatal. Other options, such as IcCAA endoscopic embolization, while attempting to preserve the ICA flow, showed no significant benefit in relation to $\mathrm{CN}$ compression symptomatology ${ }^{21}$.

Another aspect related to the ICA therapeutic occlusion in the treatment of ICCAA is the potential 
hemodynamic overload of the intracranial circulation, which may lead to the appearance of de novo aneurysms. It is believed that $1-10 \%$ of patients undergoing carotid occlusion will develop de novo aneurysms, which represents a rate higher than the expected for the general population ${ }^{29,30}$. In addition, the presence of multiple aneurysms is associated with the appearance of new aneurysmal lesions, contributing to the theory of the concomitant occurrence of structural weakness of the vessel wall. Notably, the only patient in the series who developed a de novo aneurysm during the study was the one with multiple aneurysms.
Based on the analysis of the results obtained under the conditions of the present study, we conclude that the dCCF endovascular treatment provided an improvement in retroocular pain, proptosis and hyperemia, and of the symptoms related to the involvement of CN III, IV and VI. In patients with ICCAA, endovascular treatment showed improvement of the pain and of the symptoms related to CN IV, V and, mainly, III and VI. Thus, endovascular treatment of direct carotidcavernous fistulas and aneurysms of the intracavernous portion of the internal carotid artery has been shown to be a safe method, with low complication rates.

\title{
R E S U M O
}

\begin{abstract}
Objetivo: avaliar o tratamento endovascular de lesões vasculares da artéria carótida interna $(\mathrm{ACI})$, segmento cavernoso, realizado na Santa Casa de São Paulo. Métodos: estudo descritivo, retrospectivo e prospectivo, de pacientes com aneurisma da porção cavernosa da $\mathrm{ACl}$ ou com fístulas carótido-cavernosas diretas (FCCd) submetidos a tratamento endovascular. Resultados: foram incluídos 26 pacientes com aneurismas intracavernosos e dez com FCCd. Todos os aneurismas foram tratados com oclusão da ACl. Os com FCCd foram tratados com oclusão, em sete casos, e com oclusão seletiva da fístula nos outros três. Houve melhora da dor e proptose ocular em todos os pacientes com FCCd. Nos pacientes com aneurisma intracavernoso, a incidência de dor retro-orbitária caiu de 84,6\% para $30,8 \%$ após o tratamento. Após o tratamento endovascular houve uma melhora importante da disfunção de nervos cranianos afetados em ambos os grupos, sobretudo no nervo oculomotor. Conclusão: o tratamento endovascular trouxe melhora para os pacientes deste estudo, especialmente nos critérios dor e acometimento do nervo oculomotor.
\end{abstract}

Descritores: Fístula Carotidocavernosa. Embolização Terapêutica. Lesões das Artérias Carótidas.

\section{REFERENCES}

1. Dolenc V. Direct microsurgical repair of intracavernous vascular lesions. J Neurosurg. 1983;58(6):824-31.

2. Ducruet AF, Albuquerque FC, Crowley RW, McDougall CG. The evolution of endovascular treatment of carotid cavernous fistulas: a single-center experience. World Neurosurg. 2013;80(5):538-48.

3. Debrun GM, Viñuela F, Fox AJ, Davis KR, Ahn HS. Indications for treatment and classification of 132 carotid-cavernous fistulas. Neurosurgery. 1988;22(2):285-9.

4. Ellis JA, Goldstein H, Connolly ES Jr, Meyers PM. Carotid-cavernous fistulas. Neurosurg Focus. 2012;32(5):E9.

5. Gemmete JJ, Ansari SA, Gandhi DM. Endovascular techniques for treatment of carotid-cavernous fistula. J Neuroophthalmol. 2009;29(1):62-71.

6. Cho KC, Seo DH, Choe IS, Park SC. Cerebral hemorrhage after endovascular treatment of bilateral traumatic carotid cavernous fistulae with covered stents. J Korean Neurosurg Soc. 2011;50(2):126-9.
7. Kim JW, Kim SJ, Kim MR. Traumatic carotid-cavernous sinus fistula accompanying abducens nerve (VI) palsy in blowout fractures: missed diagnosis of 'white-eyed shunt'. Int J Oral Maxillofac Surg. 2013;42(4):470-3.

8. Mercado GB, Irie K, Negoro M, Moriya S, Tanaka T, Ohmura $\mathrm{M}$, et al. Transvenous embolization in spontaneous direct carotid-cavernous fistula in childhood. Asian J Neurosurg. 2011;6(1):45-8.

9. Wang Q, Chen G. Endovascular treatment of bilateral multiple carotid-cavernous fistulas in a patient with Ehlers-Danlos Syndrome. J Neurol Surg A Cent Eur Neurosurg. 2013;74 Suppl 1:e41-4.

10. Conti MLM, Santos ARL, Aguiar GB, Lazarini PR, Jory M, Tachibana RH, et al. Endovascular treatment of iatrogenic pseudoaneurysm and delayed carotid-cavernous fistula following trans-sphenoidal surgery. Rev chil neurocir. 2012;38(2):147-50.

11. Wang YL, Ma J, Li YD, Ding PX, Han XW, Wu G. Application of the Willis covered stent for the management of posttraumatic carotid-cavernous fistulas: an 
initial clinical study. Neurol India. 2012;60(2):180-4.

12. Newton TH, Hoyt WF. Dural arteriovenous shunts in the region of the cavernous sinus. Neuroradiology. 1970;1(2):71-81.

13. Kaplan JB, Bodhit AN, Falgiani ML. Communicating carotid-cavernous sinus fistula following minor head trauma. Int J Emerg Med. 2012;5(1):10.

14. Do an S, Salman MC, Deren O, Geyik S. Carotid-cavernous fistula in term pregnancy due to spontaneous rupture of carotid-cavernous aneurysm. J Obstet Gynaecol Res. 2012;38(2):427-30.

15. Kwon HJ, Jin SC. Spontaneous healing of iatrogenic direct carotid cavernous fistula. Interv Neuroradiol. 2012;18(2):187-90.

16. Halbach VV, Hieshima GB, Higashida RT, Reicher M. Carotid cavernous fistulae: indications for urgent treatrment. AJR Am J Roentgenol. 1987;149(3):587-93.

17. Halbach VV, Higashida RT, Barnwell SL, Dowd CF, Hieshima GB. Transarterial platinum coil embolization of carotid-cavernous fistulas. AJNR Am J Neuroradiol. 1991;12(3):429-33.

18. Horton JA, Jungreis CA, Stratemeier PH. Sharp vascular calcifications and acute balloon rupture during embolization. AJNR Am J Neuroradiol. 1991;12(6):1070-3.

19. Iwaisako K, Toyota S, Ishihara M, Shibano K, Harada Y, Iwatsuki K, et al. Intracerebral hemorrhage caused by ruptured intracavernous carotid artery aneurysm. Case report. Neurol Med Chir. 2009;49(4):155-8.

20. Vasconcellos LP, Flores JAC, Veiga JCE, Conti MLM, Shiozawa P. Presentation and treatment of carotid cavernous aneurysms. Arq Neuro-Psiquiatr. 2008;66(2a):189-93.

21. Morita K, Sorimachi T, Ito Y, Nishino K, Jimbo Y, Kumagai $T$, et al. Intra-aneurysmal coil embolization for large or giant carotid artery aneurysms in the cavernous sinus. Neurol Med Chir. 2011;51(11):762-6.

22. Lee N, Jung JY, Huh SK, Kim DJ, Kim DI, Kim J. Distinction between intradural and extradural aneurysms involving the paraclinoid internal carotid artery with T2-Weighted three-dimensional fast spin-echo magnetic resonance imaging. J Korean Neurosurg Soc. 2010;47(6):437-41.
23. Lee AG, Mawad ME, Baskin DS. Fatal subarachnoid hemorrhage from the rupture of a totally intracavernous carotid artery aneurysm: case report. Neurosurgery. 1996;38(3):596-8; discussion 598-9.

24. Choulakian A, Drazin D, Alexander MJ. Endosaccular treatment of 113 cavernous carotid artery aneurysms. J Neurointerv Surg. 2010;2(4):359-62.

25. Vasconcellos LP, Flores JAC, Conti MLM, Veiga JCE, Lancellotti CLP. Spontaneous thrombosis of internal carotid artery: a natural history of giant carotid cavernous aneurysms. Arq Neuro-Psiquiatr. 2009;67(2a):278-83.

26. van Rooij WJ. Endovascular treatment of cavernous sinus aneurysms. AJNR Am J Neuroradiol. 2012;33(2):323-6.

27. Field $M$, Jungreis $C A$, Chengelis $N$, Kromer $H$, Kirby $L$, Yonas $\mathrm{H}$. Symptomatic cavernous sinus aneurysms: management and outcome after carotid occlusion and selective cerebral revascularization. AJNR Am J Neuroradiol. 2003;24(6):1200-7.

28. Rathore YS, Chandra PS, Kumar R, Singh M, Sharma MS, Suri A, et al. Monitored gradual occlusion of the internal carotid artery followed by ligation for giant internal carotid artery aneurysms. Neurol India. 2012;60(2):174-9.

29. Elhammady MS, Wolfe SQ, Farhat H, Ali Aziz-Sultan $M$, Heros RC. Carotid artery sacrifice for unclippable and uncoilable aneurysms: endovascular occlusion vs common carotid artery ligation. Neurosurgery. 2010;67(5):1431-6; discussion 1437.

30. Suzuki MT, Aguiar GB, Jory M, Conti ML, Veiga JC. De novo basilar tip aneurysm. Case report and literature review. Neurocirugia. 2011;22(3):251-4.

Received in: 09/08/2016

Accepted for publication: 22/09/2016

Conflict of interest: none.

Source of funding: none.

\section{Mailing address:}

Guilherme Brasileiro de Aguiar

E-mail: guilhermebraguiar@yahoo.com.br jcemveiga@uol.com.br 